\title{
Effect of swimming on reinnervation of rat skeletal muscle
}

\author{
G. J. HERBISON, M. MAZHER JAWEED, AND J. F. DITUNNO \\ From the Department of Rehabilitation Medicine, Thomas Jefferson University, \\ Philadelphia, Pennsylvania, U.S.A.
}

SYNOPSIS There are no studies that define the optimum intensity or time to begin exercising reinnervating muscle. Through overwork of reinnervating muscle, accomplished by synergistic tenotomy, we developed a working hypothesis. This hypothesis was tested on a physiological model. In the present study, the sciatic nerve of five groups of rats was crushed. One group served as the control and the remaining animals were exercised by swimming with weights attached to their tails for one or two hours each day (early reinnervation group) or four weeks (late reinnervating group) after crush denervation. The evaluation of muscle weights, fibre types, and protein concentration indicate that intense swimming (two hours every day) does not enhance the repair of reinnervation muscle. An evaluation of total proteins suggests that a high workload may be hazardous in the early phase of reinnervation. This study tends to confirm the hypothesis that when there are too few contractile units, as presumably is the case in early reinnervation, exercise inhibits the reinnervation process.

Exercise is a basic therapeutic procedure in the management of neuromuscular disease, yet far less is known of its applications than, say, chemotherapeutic agents in infectious disease. Fundamental knowledge is lacking in areas one would deem crucial. What should be the intensity of exercises in a given type of impairment? What is the proper duration of exercise? One hears opinions regarding these variables but nowhere can one find solid principles.

Several reports have indicated that patients with disease of the lower motoneurone lost strength after excessive activity (Lovett, 1917; Kendall and Kendall, 1939; Lundervold, 1942; Green, 1949; Seddon, 1949; Hyman, 1953; Mitchell, 1953; Bennett and Knowlton, 1958; Hník, 1962). Clinical studies designed to determine the effect of exercise after neuronal damage have indicated that exercise does not damage muscle but, on the contrary, they have consistently borne out the efficacy of brief repetitive therapeutic exercises (Delorme et al., 1948; Gurewitsch, 1950; Kabat, 1950; Huddleston, 1952; Russell and Fischer-Williams, 1954; Darcus, 1955; Lenman, 1959; Muller, 1970).
The type of activity engaged in by the patients, however, may be a more critical factor than the exercise itself. In clinical reports which have reflected the hazards of exercise, the activities were prolonged, whereas in the studies demonstrating an improvement in strength, brief maximal or submaximal exercises were performed only a few times every day. It appears that muscles might be damaged only if subjected to continuous exercise-that is, exercise performed for long periods of time throughout the day.

Because of the importance of determining when to initiate exercise in the period of reinnervation and the absence of any clinical or basic research suggesting the optimal time to begin stressing muscle, we began to establish dose response curves for exercise in reinnervating muscle (Herbison et al., 1973a, b, 1974a; Jaweed et al., 1974). As a first step we studied the effect of overwork, induced by tenotomy of synergistic muscles, on reinnervating rat soleus and plantaris muscles (Herbison et al., 1973a, b; Herbison et al., 1974a; Jaweed et al., 1974). The overwork of muscles accomplished by elimination of 
synergistic muscles two and three weeks after sciatic nerve crush (Herbison et al., 1973b; Herbison et al., 1974b) yielded a decrease in the content of muscle proteins in the former and a significant increase of non-collagenous proteins in the latter. This was interpreted to mean that muscle might be damaged when stressed too soon in or before the reinnervation period. Because of these findings, we formulated the following hypothesis: muscle damage might occur during the course of reinnervation when the number of contractile units (NCU) are too few or the intensity (I) of exercise is too great (Herbison et al., 1973b). This can be expressed as a ratio: $\mathrm{NCU} / \mathrm{I}=\mathrm{C}$, where $\mathrm{C}$ is a limiting value below which reinnervating muscle would be damaged.

The purpose of the present investigation was to test this hypothesis by using a physiological model rather than after performing synergistic tenotomy (Herbison et al., 1973a, b; Herbison et al., 1974a; Jaweed et al., 1974).

\section{METHODS}

Pre-anaesthetized (pentobarbitone $50 \mathrm{mg} / \mathrm{kg}$ body weight) adult female Wistar rats $(\mathrm{N}=40)$ were equally divided into five groups (A-E), and the sciatic nerve was crushed bilaterally at the sciatic notch (Herbison et al., 1973a). We have previously demonstrated that, by this method of denervation, reinnervation takes place between the second and third week after the nerve crush (Herbison et al., 1973b). The animals were housed, singly, in wired cages and maintained under optimal conditions on ad libitum purina food and water. Two groups (B and C) were initiated to exercise three weeks after denervation in a rectangular tank $\left(\frac{1}{2} \times 1 \times 1 \frac{1}{2} \mathrm{cu}\right.$ feet $)$ filled with water at $32-35^{\circ} \mathrm{C}$. The animals were weighted with rubber stoppers (18 g) attached to their tails and exercised in groups of eight to 12 animals at a time. Group B animals swam for one hour each day for five days a week for three weeks while the group $\mathbf{C}$ animals exercised two hours every day for the same period. Similarly, two other groups (D and E) were initiated to exercise four weeks after denervation and trained for two weeks. Group D swam one hour each day and group $E$ for two hours Group A did not exercise and therefore served as the sedentary control. Before exercising the animals were progressively trained over a one week period to familiarize them with a specific regimen of the swimming exercise (Jaweed et al., 1974a).

TABLE 1

EFFECT OF DIFFERENT WORKLOADS OF SWIMMING ON MUSCLE WEIGHT AND PROTEIN CONTENT, OF GASTROCNEMIUS MUSCLE OF ADULT RATS*

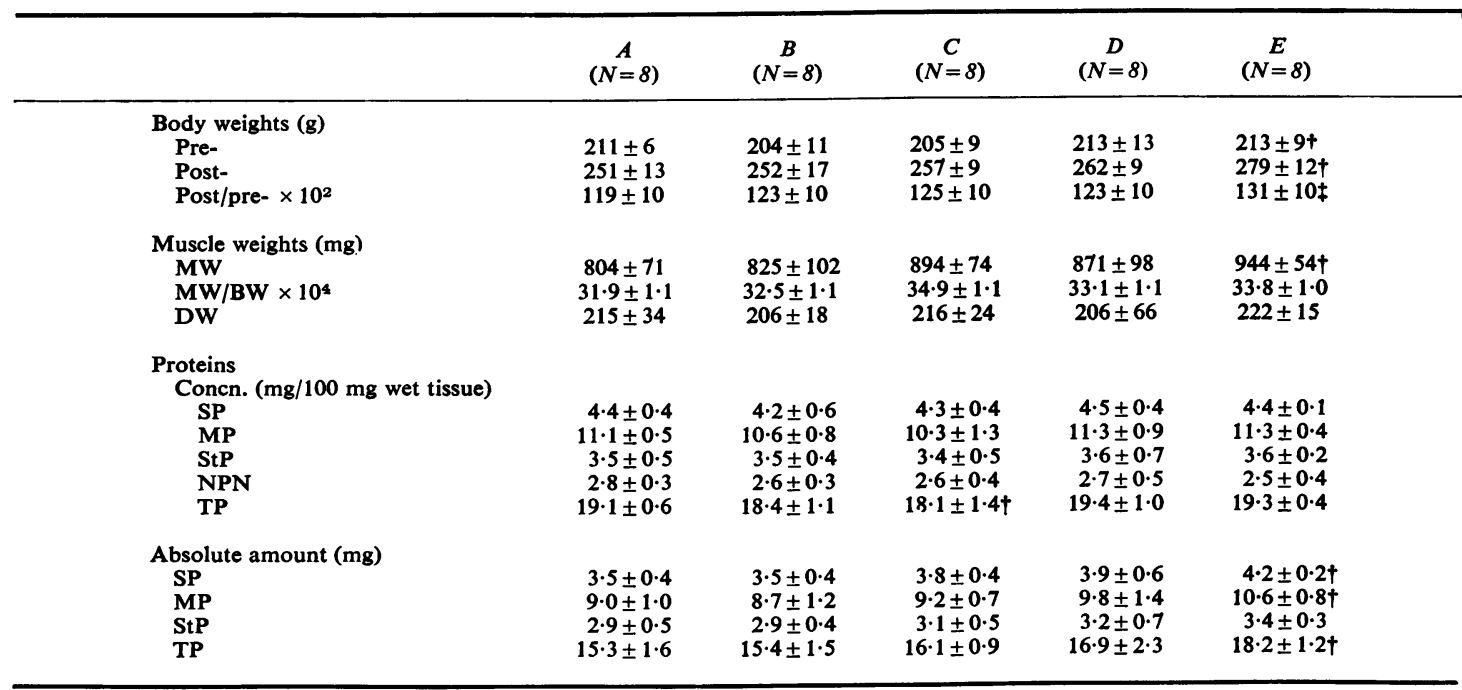

* Exercise was initiated in the early (three weeks post-denervation) and late (four weeks post-denervation) stages of reinnervation (means \pm standard deviations).

Group: $A=$ Sedentary control; $B=$ swimmers: exercised three weeks after denervation $1 \mathrm{hr} / \mathrm{d}$; $C=$ exercised three weeks after denervation $2 \mathrm{hr} / \mathrm{d} ; \mathrm{D}=$ exercised four weeks after denervation $1 \mathrm{hr} / \mathrm{d} ; \mathrm{E}=$ exercised four weeks after denervation $2 \mathrm{hr} / \mathrm{d} ; \mathbf{S P}=$ sarcoplasmic proteins; $\mathbf{M P}=$ myofibrillar proteins; $\mathbf{S t P}=$ stromal proteins; $\mathbf{T P}=$ total proteins; NPN = non-protein nitrogen. $+\mathbf{P}<0.05$ $\mp \mathbf{P}<0.01$. 
All groups were decapitated six weeks after denervation under the influence of anaesthesia (pentobarbitone $50 \mathrm{mg} / \mathrm{kg}$ body weight) and three muscles of the gastrocnemius-soleus-plantaris complex were excised and the wet and dry weights were obtained. The gastrocnemius muscle was used for determination of collagenous and non-collagenous proteins (Gordon et al., 1966), while soleus and plantaris muscles were used for the activity of myosinATPase (Padykula and Herman, 1955) and trichrome stain (Engel and Cunningham, 1964) in $6 \mu \mathrm{m}$ thick frozen sections as described previously (Herbison et al., 1973b). Experimental data were analysed by Neuman-Keul's method.
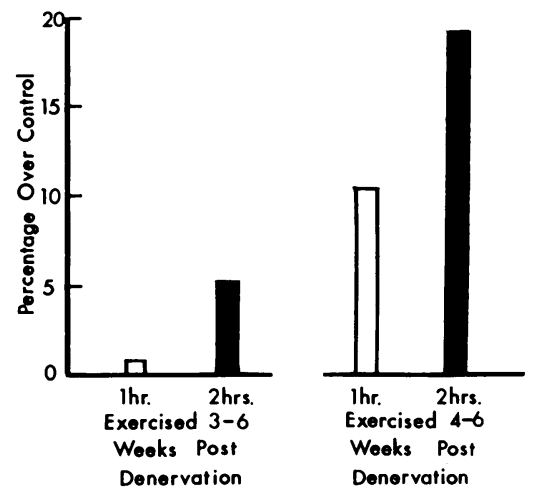

FIGURE Effect of swimming on the content (in $\mathrm{mg}$ per muscle) of total proteins in gastrocnemius muscle of adult rats after sciatic nerve crush. Rats were killed six weeks after crush denervation. Groups $B$ and $C$ (3-6) were exercised from the third to the sixth week after denervation for one and two hours, respectively. Animals in groups $D$ and $E(4-6)$ were exercised from the fourth to the sixth week after denervation for one and two hours, respectively. Note the trend of a linear relationship between the protein content and the time of onset and duration of exercise.

\section{RESULTS}

The initial body weights (BW) of the rats were between 200 and $215 \mathrm{~g}$. Whereas groups A-D were identical in later body weights after six weeks, group $\mathrm{E}$ was significantly $(\mathrm{P}<0.01)$ different from the control. A similar pattern was noted in the wet muscle weight (MW) of group $\mathrm{E}(\mathrm{P}<0.05)$. However, $\mathrm{MW} / \mathrm{BW}$ ratio and dry weights of groups $\mathrm{A}-\mathrm{E}$ were not significantly different (Table 1).
Protein concentrations of sarcoplasmic, myofibrillar, stromal, and total proteins were the same in all five groups. Group $\mathrm{C}$ total protein concentration was significantly lower $(\mathrm{P}<0.05)$ than the remaining four groups (Table 1). Except for group $\mathrm{E}$ there were no significant differences in absolute proteins (Table 1 and Figure). Fibre diameters and percentage of fibre types were also similar in all five groups (Table 2). There was no evidence of split fibres or central nuclei to suggest any myopathy caused by exercise.

\section{DISCUSSION}

Swimming is a mild form of endurance exercise and has not been found to stimulate muscle hypertrophy (Jaweed et al., 1974b). Therefore, it is not surprising to see that the muscle weight ratios or dry weights did not differ in all five groups. Group E muscle and body weights were greater than the remaining four groups. Since muscle weights increase in proportion to body weight (unpublished observations) the elevated muscle weights in group $\mathrm{E}$ can be explained merely on the basis of this relationship and not entirely related to the stimulus of exercise.

Sarcoplasmic, myofibrillar, and stromal protein concentrations were not significantly different in any of the groups. This is consistent with our previous findings on proteins in overwork (Herbison et al., 1973). As we demonstrated earlier (Herbison et al., 1974), during the process of reinnervation the concentration of proteins does not rise until the muscle bulk is restored in the recovery phase. Any physiological process that is beneficial to reinnervation will probably divert the processes of synthesis towards a faster repair, which may be expressed in absolute amounts of proteins rather than alterations in protein concentration. In case of damage, however, concentration may be affected. Gutmann and associates (1971) have also observed that protein concentrations remain low until other signs of reinnervation are apparent.

The concentration $(\mathrm{mg} \%)$ of total proteins (TP) was found lower than control in group C where swimming was initiated three weeks after crush denervation and exercise was carried out two hours every day. This finding, therefore, supports the hypothesis (Herbison et al., 1973b) 
TABLE 2

FIBRE DIAMETER AND COMPOSITION OF FIBRE TYPES IN REINNERVATING SOLEUS AND PLANTARIS MUSCLES AFTER DIFFERENT WORKLOADS OF SWIMMING $(\mathrm{x} \pm \mathrm{SD})$

\begin{tabular}{lccccc}
\hline & $\begin{array}{c}A \\
(N=5)\end{array}$ & $\begin{array}{c}B \\
(N=5)\end{array}$ & $\begin{array}{c}C \\
(N=5)\end{array}$ & $\begin{array}{c}D \\
(N=5)\end{array}$ \\
& & & & & \\
$(N=5)$
\end{tabular}

$\overline{\mathbf{x}} \pm \mathrm{SD}=$ Mean \pm standard deviation.

Type $\mathrm{I}=$ Low myosin-ATPase (pH 9.4) active fibres.

Type II = High myosin-ATPase (pH 9.4) active fibres.

relating the number of contractile units to the intensity of exercise. Group $\mathrm{C}$ animals swam for two hours, whereas group B was exercised for only one hour every day three weeks postdenervation. When swimming was initiated, both groups $\mathrm{B}$ and $\mathrm{C}$ were in the earliest stage of reinnervation (Herbison et al., 1973b) and presumably had a paucity of functional motor units, as indicated by the content of total proteins. Group C was possibly affected because the number of contractile units were too few to maintain the NCU/I ratio above the critical level necessary to prevent destruction of muscle tissue.

Absolute amount of proteins (in milligrams) in groups $\mathbf{B}$ through $\mathbf{E}$ compared with group $\mathbf{A}$ (Figure) also tends to confirm our hypothesis. Although the differences between the five groups are not marked, there seems to be a trend reflecting lower absolute protein content in the animals exercised three weeks after denervation compared with the group that began swimming four weeks after nerve crush. This supports our hypothesis that an increase in the number of contractile units protects against the severity of the physical activity (Herbison et al., 1973b; 1974a).

The fibre diameters and types were unchanged by swimming (Table 2). Fibre diameter measurements, however, have not been found to be a sensitive index of muscle hypertrophy. Gutmann and his coworkers found that, where the muscle weight increased $55 \%$ after synergistic tenotomy, the fibre diameters were only $11 \%$ greater than control values (Gutmann et al., 1973). In the present study and after synergistic tenotomyo (Herbison et al., 1973a, b) we did not find that exercise carried out during reinnervation pro- $\mathbb{Q}$ duced any myopathic changes such as fibre split-o $\bar{z}$ ting, central nuclei, or fibre necrosis. Such changes may not be a sensitive index of muscleo damage unless the activity is excessive as demonstrated by Reitsma (1969) and Van Linge (1962): who exercised animals intensively after elimination of the synergistic muscles.

This study was partially supported by an Easter Seals Research Grant No. N-7214 and a Government General Research Support Grant No. RR-5414 to Thomas Jefferson University. The authors are grateful to A. Bohuslowsky and R. Graham for their technical assistance.

\section{REFERENCES}

Bennett, R. L., and Knowlton, G. C. (1958). Overwork weakness in partially denervated skeletal muscle. Clinical Orthopaedics, No. 12, 22-29.

Darcus, H. D. (1955). A strain-gauge dynamometer for the measurement of the strength of isometric contraction and for the training of muscles. In Poliomyelitis. Papers and Discussions Presented at the Third International Poliomyelitis Conference, pp. 446-451. Lippincott: Philadelphia.

DeLorme, T. L., Schwab, R. S., and Watkins, A. L. (1948). The response of the quadriceps femoris to progressiveresistance exercises in poliomyelitic patients. Journal of Bone and Joint Surgery, 30A, 834-847. 
Engel, W. K., and Cunningham, G. G. (1963). Rapid examination of muscle tissue. An improved trichrome methed for fresh-frozen biopsy sections. Neurology (Minneap.), 13, 919-923.

Gordon, E. E., Kowalski, K., and Fritts, M. (1966). Muscle proteins and DNA in rat quadriceps during growth. American Journal of Physiology, 210, 1033-1040.

Green, T. W. (1949). The management of poliomyelitis: the convalescent stage. Poliomyelitis. Papers and Discussions Presented at the First International Poliomyelitis Conference, pp. 165-185. Lippincott: Philadelphia.

Gurewitsch, A. D. (1950). Intensive graduated exercises in early infantile paralysis. Archives of Physical Medicine, 31, 213-218.

Gutmann, E. (1962). Metabolic reactibility of the denervated muscle. In The Denervated Muscle, pp. 377-432. Edited by E. Gutmann. Czechoslovak Academy of Sciences: Prague.

Gutmann, E., Schiaffino, S., and Hanzlikova, V. (1971). Mechanism of compensatory hypertrophy in skeletal muscle of the rat. Experimental Neurology, 31, 451-464.

Herbison, G. J., Jaweed, M. M., and Ditunno, J. F., Jr (1973a). Reinnervating muscle in rats: the effect of overwork. Archives of Physical Medicine and Rehabilitation, 54, 511-514.

Herbison, G. J., Jaweed, M. M., Ditunno, J. F., and Scott, C. M. (1973b). Effect of overwork during reinnervation of rat muscle. Experimental Neurology, 41, 1-14.

Herbison, G. J., Jaweed, M. M., Gordon, E. E., and Ditunno, J. F., Jr (1974a). Overwork of denervated skeletal muscle: effect on muscle proteins in rat. Archives of Physical Medicine and Rehabilitation, 55, 202-205.

Herbison, G. J., Jaweed, M. M., Scott, C. M., and Ditunno, J. F., Jr (1974b). Muscle weight and protein content of rat skeletal muscle following sciatic nerve crush. Archives of Physical Medicine and Rehabilitation. (In press.)

Hník, P. (1962). Rate of denervation muscle atrophy. In The Denervated Muscle, pp. 341-375. Edited by E. Gutmann. Czechoslovak Academy of Sciences: Prague.

Huddleston, O. L., Austin, E., Moore, R. W., Cailliet, R., and Rubin, D. (1952). Anterior poliomyelitis. Physical treatment in Southern California. British Journal of Physical Medicine, 15, 75-87.

Hyman, G. (1953). Poliomyelitis. Lancet, 1, 852.

Jaweed, M. M., Herbison, G. J., and Ditunno, J. F. (1974). Effect of swimming on compensatory hypertrophy of reinnervating soleus and plantaris muscles. American Journal of Physical Medicine, 53, 35-40.

Jaweed, M. M., Herbison, G. J., Ditunno, J. F., and Gordon, E. E. (1974). Weight of rat ventricle in different exercises. Archives of Physical Medicine and Rehabilitation. (In press.)

Kabat, H. (1950). Studies on neuromuscular dysfunction, XIII: new concepts and techniques of neuromuscular reeducation for paralysis. Permanente Foundation Medical Bulletin, 8, 121-143.

Kendall, H. O., and Kendall, F. P. (1939). Care During the Recovery Period in Paralytic Poliomyelitis. U.S. Public Health Service. Public Health Bulletin No. 242. U.S. Government Printing Office: Washington.

Lenman, J. A. R. (1959). A clinical and experimental study of the effects of exercise on motor weakness in neurological disease. Journal of Neurology, Neurosurgery, and Psychiatry, 22, 182-194.

Lovett, R. W. (1917). The Treatment of Infantile Paralysis. Blakiston: Philadelphia.

Lundervold, A., and Seyffarth, H. (1942). Electromyographic investigations of poliomyelitic paresis during the training up of the affected muscles and some remarks regarding the treatment of paretic muscles. Acta Psychiatrica et Neurologica, 17, 69-87.

Mitchell, G. P. (1953). Poliomyelitis and exercise. Lancet, 2, 90-91.

Muller, E. A. (1970). Influence of training and of inactivity on muscle strength. Archives of Physical Medicine and Rehabilitation, 51, 449-462.

Padykula, H. A., and Herman, E. (1955). The specificity of the histochemical method for adenosine triphosphatase. Journal of Histochemistry and Cytochemistry, 3, 170-195.

Reitsma, W. (1969). Skeletal muscle hypertrophy after heavy exercise in rats with surgically reduced muscle function. American Journal of Physical Medicine, 48, 237-258.

Russell, W. R., and Fischer-Williams, M. (1954). Recovery of muscular strength after poliomyelitis. Lancet, 1, 330-333.

Seddon, H. J. (1949). Discussion of chapter 5. The management of poliomyelitis. The convalescent stage. In Poliomyelitis. Papers and Discussion Presented at the First International Poliomyelitis Conference, pp. 186-198. Lippincott: Philadelphia.

Van Linge, B. (1962). The response of muscle to strenuous exercise. An experimental study in the rat. Journal of Bone and Joint Surgery, 44B, 711-721. 